\title{
Comparison of observed and model-computed low frequency circulation and hydrography on the New England Shelf
}

\author{
G. W. Cowles, ${ }^{1}$ S. J. Lentz, ${ }^{2}$ C. Chen, ${ }^{1}$ Q. Xu, ${ }^{1}$ and R. C. Beardsley ${ }^{2}$ \\ Received 14 June 2007; revised 14 April 2008; accepted 13 June 2008; published 9 September 2008.
}

[1] The finite volume coastal ocean model (FVCOM) is configured to study the interannual variability of circulation in the Gulf of Maine (GoM) and Georges Bank. The FVCOM-GoM system incorporates realistic time-dependent surface forcing derived from a high-resolution mesoscale meteorological model (MM5) and assimilation of observed quantities including sea surface temperature and salinity and temperature fields on the open boundary. An evaluation of FVCOM-GoM model skill on the New England shelf is made by comparison of computed fields and data collected during the Coastal Mixing and Optics (CMO) Program (August 1996-June 1997). Model mean currents for the full CMO period compare well in both magnitude and direction in fall and winter but overpredict the westward flow in spring. The direction and ellipticity of the subtidal variability correspond but computed magnitudes are around 20\% below observed, partially due to underprediction of the variability by MM5. Response of subtidal currents to wind-forcing shows the model captures the directional dependence, as well as seasonal variability of the lag. Hydrographic results show that FVCOM-GoM resolves the spatial and temporal evolution of the temperature and salinity fields. The modelcomputed surface salinity field compares well, except in May when there is no indication of the fresh surface layer from the Connecticut River discharge noted in the observations. Analysis of model-computed results indicates that the plume was unable to extend to the mooring location due to the presence of a westward mean model-computed flow during that time that was stronger than observed. Overall FVCOM-GoM captures well the dynamics of the mean and subtidal flow on the New England shelf.

Citation: Cowles, G. W., S. J. Lentz, C. Chen, Q. Xu, and R. C. Beardsley (2008), Comparison of observed and model-computed low frequency circulation and hydrography on the New England Shelf, J. Geophys. Res., 113, C09015, doi:10.1029/2007JC004394.

\section{Introduction}

[2] The finite volume coastal ocean model (FVCOM) [Chen et al., 2003] has been configured to investigate circulation and water property evolution in the Gulf of Maine (GoM) and Georges Bank (GB) region with realistic timedependent forcing. This FVCOM-GoM system is currently being used to examine the impact of interannual variability in the hydrography, mean currents, and mixing on the Gulf of Maine and Georges Bank ecosystem. Focus species include scallops and critical groundfish such as cod, haddock, and yellowtail flounder. The model system has been integrated from 1 January 1995 to present time and a thorough examination of model skill is currently underway. To study interannual variability, it is critical that the controlling processes and

\footnotetext{
${ }^{1}$ Department of Fisheries Oceanography, School for Marine Sciences and Technology, University of Massachusetts-Dartmouth, New Bedford, Massachusetts, USA.

${ }^{2}$ Department of Physical Oceanography, Woods Hole Oceanographic Institution, Woods Hole, Massachusetts, USA.
}

Copyright 2008 by the American Geophysical Union. 0148-0227/08/2007JC004394\$09.00 factors are understood and resolved in the model. Tidal amplitude and phase for the Gulf of Maine and New England shelf have been examined and model data comparisons show close agreement (C. Chen et al., Tidal dynamics in the Gulf of Maine and New England Shelf: An application of FVCOM, submitted to J. Geophys. Res., 2008, hereinafter referred to as Chen et al., submitted manuscript, 2008). Recent effort is focused on validating the response of the model to realistic boundary forcing across a range of timescales from several days to years. This requires comparison with experimental data collected within our domain during the period of integration. This paper presents the results of one such validation effort which focuses on the New England shelf (NES) region.

[3] Much scientific effort has been devoted to understanding the dynamics and hydrography of the NES. A recent experiment, the Coastal Mixing and Optics Study (CMO) [Dickey and Williams, 2001] took place between August 1996 and June 1997, a time which lies within the FVCOM-GoM integration period. Results from the CMO Program will serve as the primary observational data set in this paper. Results from other experiments, in particular the Nantucket Shoals Flux Experiment (NSFE) [Beardsley et 


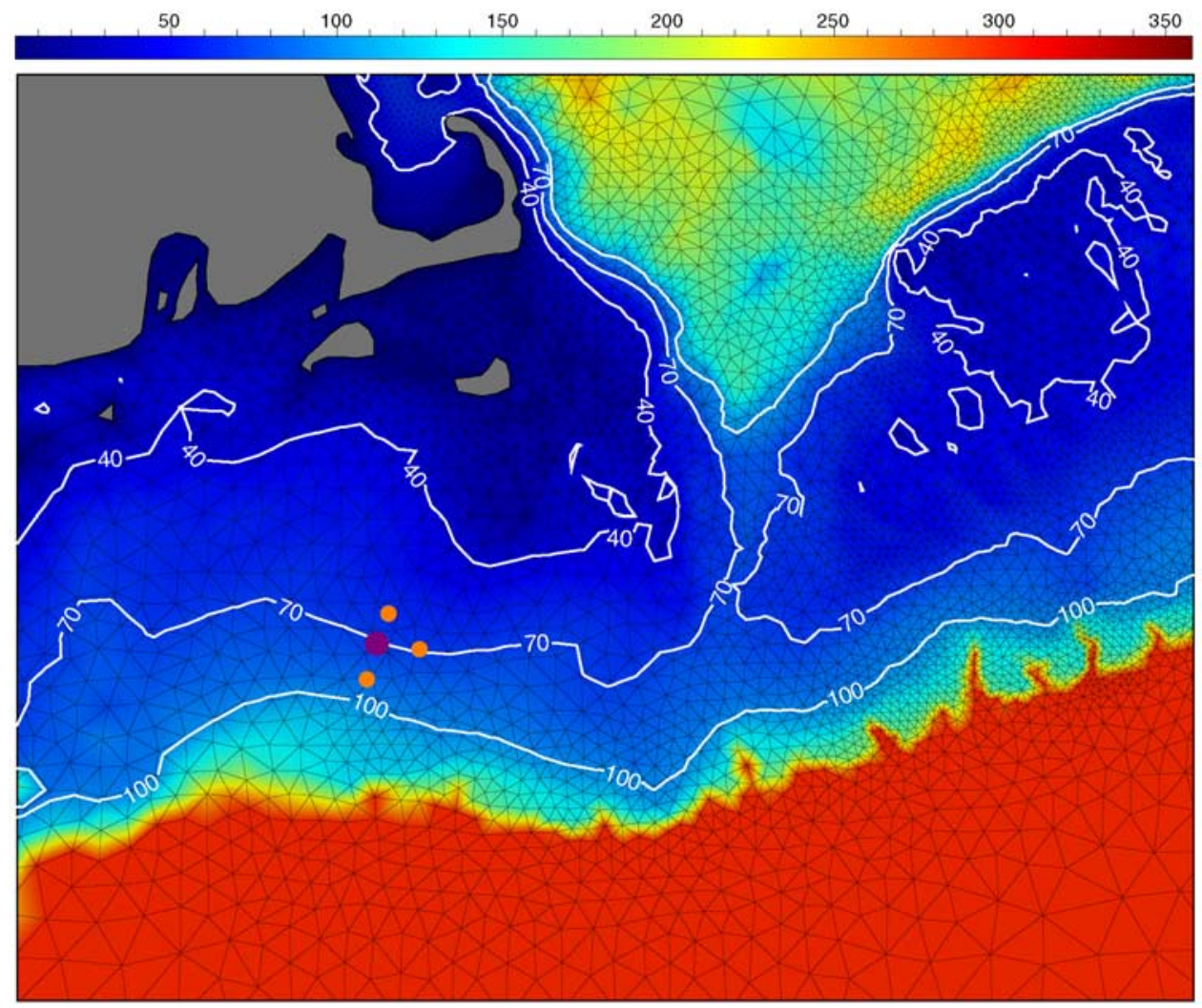

Figure 1. New England shelf region: model mesh, bathymetry (color scale at top in m), isobaths (m), and location of CMO mooring array (CMO central site denoted by large dot).

al., 1985], where relevant, are qualitatively compared with computed quantities in this paper.

[4] The CMO Program included a densely instrumented moored array which was deployed southwest of Nantucket, Massachusetts on the NES (Figure 1). Data from the array were collected from August 1996 to June 1997 and included current, hydrographic (salinity and temperature), bottom pressure, and atmospheric (surface stress, heat flux) measurements. These measurements were made to characterize the high-frequency (tidal), intermediate-frequency (several days), and low-frequency (seasonal) flow on the NES. Subsequent analysis of CMO data include investigation of the low-frequency currents [Shearman and Lentz, 2003], stratification [Lentz et al., 2003], tidal variability [Shearman and Lentz, 2004] and mixing [MacKinnon and Gregg, 2002].

[5] The NES lies south of New England, is roughly $100 \mathrm{~km}$ in width and runs roughly west-east, with the Nantucket Shoals forming the eastern terminus and the Hudson crossshelf channel the western terminus. The shelf break occurs near the $150-\mathrm{m}$ isobath. The central CMO mooring site (CMOC), where the majority of observations included in this paper were collected, is located on the $70-\mathrm{m}$ isobath (Figure 1). A prominent hydrographic feature of the NES is the front that separates the fresher, nearshore shelf water and salty slope water, known as the shelf-slope front. While this front is primarily located offshore of the CMOC site, temporal movement of the front is quite prominent and the lower reaches of the front, known as the foot, were observed inshore of the 70-m isobath periodically during the CMO. The NES exhibits a strong annual cycle of stratifi- cation which is well-mixed throughout much of the winter and strongly stratified in summer due to increased surface heating, freshwater buoyancy flux, and a reduction in wind strength. Both temperature and salinity fields are important to the density field gradients. There is a strong westward mean current of approximately $5 \mathrm{~cm} \mathrm{~s}^{-1}$ near the CMOC site, and thus advection and three-dimensional processes play an important role in shelf circulation which is heavily dependent on upstream conditions. The wind field is highly variable and characterized by light summer winds, infrequent events in fall and spring, and frequent intermediate and strong wind events through the winter. The NES is also occasionally visited by warm core rings which can alter significantly the shelf hydrography and short-term circulation structure [Beardsley et al., 1985].

[6] This paper is organized as follows: section 2 will describe the FVCOM model and outline how it has been configured to simulate the circulation in the Gulf of Maine and New England shelf; sections 3 through 7 provide comparisons of model and observed wind fields, hydrography, mean currents, variability of low-frequency currents, and correlation of currents and the wind field; section 8 discusses implications of some of the findings, focusing on SST assimilation and mean flow; and section 9 summarizes the major findings of the paper.

\section{FVCOM-GoM Model Description}

[7] FVCOM is an unstructured grid, hydrostatic primitive equation (HPE) ocean model [Chen et al., 2003]. The 


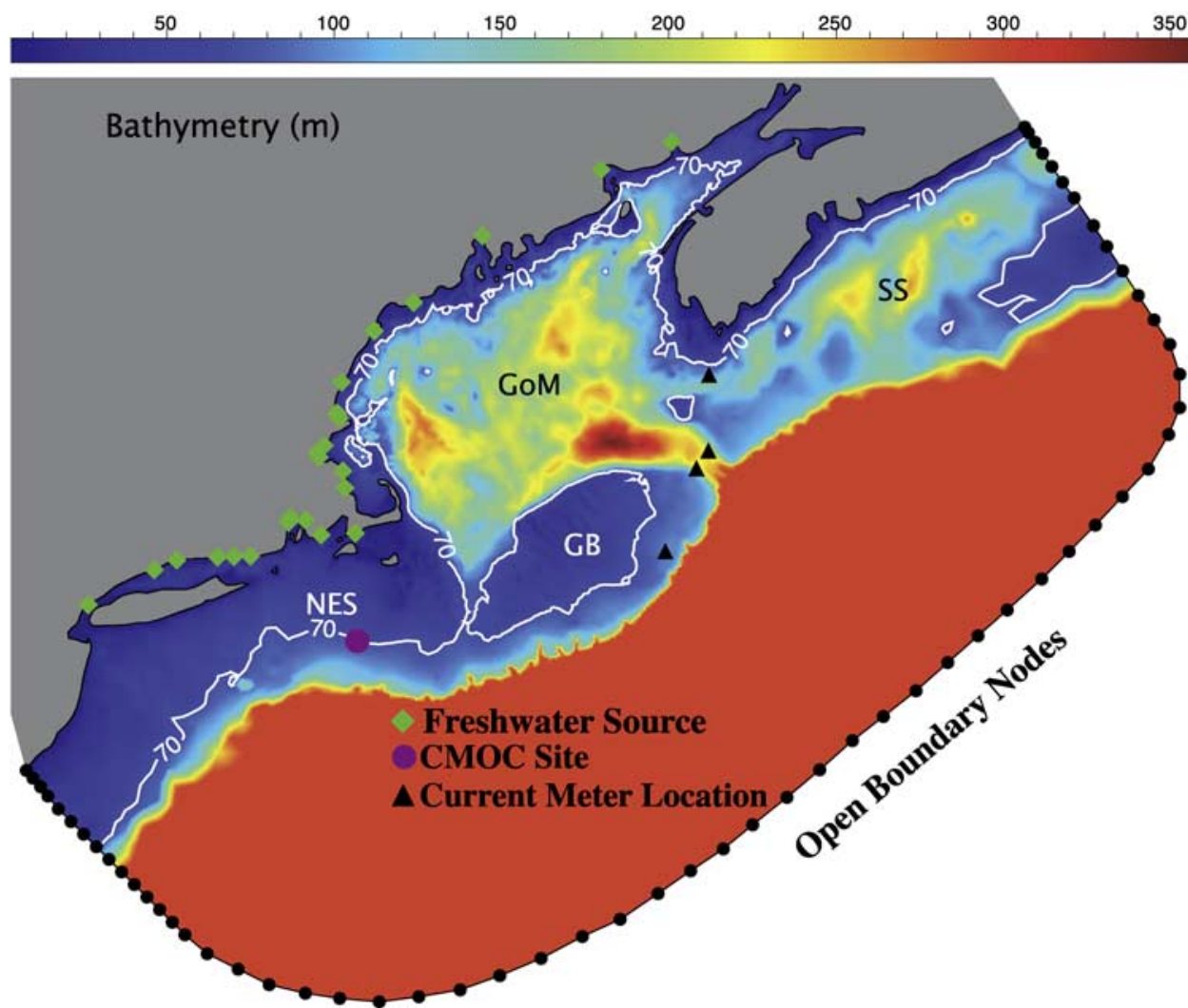

Figure 2. FVCOM-GoM domain, open boundary mesh, bathymetry (m), the CMO central site, and the locations of specified river freshwater sources within the domain.

equations are cast in a terrain-following $\sigma$-coordinate system [Phillips, 1957]. Time advancement of the model equations uses an explicit mode-splitting approach [Madala and Piacsek, 1977; Simons, 1974]. The spatial fluxes of momentum are discretized using a second-order accurate finite-volume method [Kobayashi et al., 1999]. A flux formulation for scalars (e.g., temperature, salinity) is used in conjunction with a vertical velocity adjustment to enforce exact conservation of the scalar quantities. The model is parallelized using an efficient Single Program Multiple Data (SPMD) approach [Cowles, 2008]. Domain decomposition is performed using the METIS graph partitioning libraries [Karypis and Kumar, 1998]. Message passing is coded using the Message Passing Interface (MPI) standard [MPI, 1993]. A Smagorinsky formulation [Smagorinsky, 1963] is used to parameterize horizontal diffusion and turbulent vertical mixing is calculated using the General Ocean Turbulence Model (GOTM) libraries [Burchard, 2002]. For this work, the 2.5 level Mellor-Yamada turbulence model was used [Mellor and Yamada, 1982]. To account for increased mixing due to breaking wind-driven waves, a surface diffusion boundary condition for turbulent kinetic energy [Craig and Banner, 1994] is employed in concert with a finite turbulence macro-length scale at the free surface that is dependent on significant wave height [Terray et al., 1999]. Scheme implementation and parameters used for the modified surface mixing schemes were suggested by Mellor and Blumberg [2004].

\subsection{Domain}

[8] The FVCOM model has been configured for the study of Gulf of Maine circulation, hereafter referred to as FVCOM-GoM. Three generations of model grids (GoM-G1, GoM-G2, and GoM-G3) are currently in use for a range of research applications. Model output used in the current study was generated using the coarsest mesh (GoM-G1) which contains 25,559 elements and 13,504 nodes. Thirty layers equally spaced in $\sigma$ space were used to discretize the vertical coordinate, so that the vertical resolution is $2.33 \mathrm{~m}$ at the $70-\mathrm{m}$ deep CMOC site. Model velocities are located midlayer and thus the bottom velocity is located at $1.18 \mathrm{~m}$ above bottom (mab). For comparisons between computed and observed quantities, model results are interpolated to in situ instrument locations using linear interpolation.

[9] The FVCOM-G1 domain (Figure 2) includes the entire Gulf of Maine, the Scotian Shelf (SS) to $45.2^{\circ} \mathrm{N}$, the NES, and the central Mid-Atlantic Bight south to $39.1^{\circ} \mathrm{N}$. The bathymetry is truncated at $300 \mathrm{~m}$ offshelf to reduce time step restrictions, but true bathymetry is retained inside the Gulf of Maine where the maximum depth reaches $360 \mathrm{~m}$ in Georges Basin. The mesh uses variable resolution ranging from $3 \mathrm{~km}$ on the Northeast Peak of Georges Bank to $45 \mathrm{~km}$ at the open boundary. The mesh generation was optimized to resolve the circulation on Georges Bank and the Gulf of Maine and thus the mesh in the vicinity of the NES is quite coarse, with a grid scale of $10 \mathrm{~km}$ (Figure 1). The time steps used for the external and internal modes were $12 \mathrm{sec}$ and $120 \mathrm{sec}$. The model integration time frame 
is 1 Jan 1995 to present (February 2007), encompassing the CMO period of observation. Execution was performed on the UMASS-D marine ecosystem dynamics and modeling laboratory high performance computer cluster (HPCC) Hydra using between 32 and 64 processors with associated wall clock times ranging from of 7.5 to 4 hours per month of simulated time. Runs were performed in 3-month increments, and hourly data were saved. Archived quantities include sea surface height, three-dimensional velocity components, turbulent kinetic energy, salinity, and temperature. Density is reconstructed using the standard UNESCO formulation [UNESCO, 1981].

\subsection{Forcing}

[10] Boundary forcing in the FVCOM-GoM system includes prescription of tidal elevation at the open boundary, freshwater input from major rivers within the Gulf of Maine and over the NES, and wind stress and heat flux from a meteorological model. Internal forcing includes nudgingbased data assimilation from several moored current meters on Georges Bank, temperature/salinity nudging at the open boundary, continuous nudging of satellite-derived sea surface temperature (SST), optimal interpolation of salinity and temperature using hydrographic data, and sea surface setup/ setdown modification on the Nova Scotian coast to correct for alongshelf transport. A brief description of each is provided below.

\subsubsection{Sea Surface Elevation}

[11] The tidal sea surface elevation is prescribed at the open boundary using a Julian day formulation. Tides in the model have been calibrated by comparing the five major constituents $\left(M_{2}, S_{2}, N_{2}, O_{1}\right.$, and $\left.K_{1}\right)$ at 98 observation stations within the Gulf of Maine (Chen et al., submitted manuscript, 2008).

\subsubsection{Wind Forcing and Heat Flux}

[12] Wind stress and heat flux at the free surface are derived from a local domain configuration of the fifth-generation mesoscale meteorological model (MM5) [Grell et al., 1994]. The configuration has 10-km coverage of the Gulf of Maine/ Scotian Shelf/NES regions and uses 31 layers to discretize the vertical coordinate. The model is initialized with NCAR/ NCEP weather model fields and utilizes four-dimensional data assimilation methods to incorporate all coastal NDBC environmental buoy and C-MAN surface weather data for improved model state estimates [Chen et al., 2005]. Cloud cover data from the International Satellite Cloud Climatology Project (ISCCP) are used for improved radiative flux estimates. The COARE 2.6 bulk algorithm is used to estimate the turbulent air-sea fluxes [Fairall et al., 1996]. A database of hourly outputs of wind stress components, precipitation, shortwave radiation, net longwave radiation and sensible and latent heat fluxes for 1978 to present has been generated. Fields from this database are interpolated onto the unstructured FVCOM mesh and used to provide the surface forcing for FVCOM-GoM.

\subsubsection{Freshwater Input}

[13] Freshwater input to the model domain is incorporated using USGS streamgauge data from 29 rivers. The primary rivers feeding the Gulf of Maine are, from south to north, the Merrimac, Saco, Androscoggin, Kennebec, Penobscot, St. Croix, and St. Johns. In southern New England, the majority of discharge is derived from the Housatonic,
Connecticut, Thames, Providence (Blackstone and Pawtuxet), and Taunton rivers. The surface buoyancy flux $(P-E)$ is neglected in this current FVCOM-GoM configuration. The salinity of the river inputs is specified to be $0 \mathrm{ppt}$ in order to maintain the correct freshwater flux. The temperature of the external flux is based on the model temperature at the river mouth calculated in the previous iteration.

\subsubsection{SST Nudging}

[14] Model sea surface temperature (SST) is improved by assimilation of satellite-derived SST. A high-resolution, daily SST database was constructed using objective analysis to fill in the gaps where cloud coverage restricted observations. The resulting database was interpolated onto the model grid to provide daily mean SST at all surface nodes. The data assimilation process uses a two-cycle method to nudge the model-computed daily mean value toward the observed quantity. In the first cycle, the model is integrated for a 24-hr period without SST assimilation. The model mean over this period is computed and stored. In the second cycle, the same 24-hr period is rerun with addition of a Newtonian nudging term in the temperature equation to correct the SST using the error between computed and observed daily mean. The $e$-folding scale $\left(\frac{1}{\alpha}\right)$ was $400 \mathrm{sec}$.

\subsubsection{Current Meter Nudging}

[15] Current meter data from three GLOBEC moorings (SEF, NECE, NECW, C2) on and near Georges Bank are used to nudge model fields (Figure 2). The spatial scale for the nudging was $10 \mathrm{~km}$ and temporal scale was $1 \mathrm{hr}$. Nudging, while inexpensive and trivial to implement, can generate strong horizontal and vertical shears in the assimilated currents if an inappropriate spatial weight function is selected, particularly in the Northeast Channel (NEC), the relatively narrow and deep channel at the eastern end of Georges Bank. For the model run, a vectorized spatially dependent covariance function, strongly weighted in the along-isobath direction and smoothly distributed in the vertical was used in the NEC to prohibit the model from generating an artificial recirculation inside the channel. This technique worked reasonably well with respect to enforcing water transport, but it is unclear if this method produces a realistic spatial distribution of the currents locally. We are currently working on the implementation of more advanced data assimilation methods based on the Kalman filter in FVCOM. Once validated, these methods will be utilized to improve model states in the FVCOM-GoM system.

\subsubsection{Optimal Interpolation of Hydrographic Fields}

[16] Salinity and temperature model states are improved using optimal interpolation. Hydrographic observation data from National Oceanographic Data Center (NODC) and Bedford Institute of Oceanography (BIO) databases within the model domain and simulation timeframe are merged with the background (model) fields taking into account their expected variances. The resulting merged field is optimal in the sense that it has minimal error variance. A spatial scale of $30 \mathrm{~km}$ and timescale of 72 hours were selected for the assimilation procedure. For the present model data comparison, the data (CMO observations) were not included in the optimal interpolation process.

\subsubsection{Open Boundary Nudging}

[17] In the interior of the Gulf of Maine, the mean residence time of the water masses is approximately $1-1.5$ years [Brown 
and Beardsley, 1978; Ramp et al., 1985]. Thus over a decadal scale integration period, the evolution of the hydrographic fields within the Gulf are largely controlled by boundary forcing, principally via the Scotian Shelf. Monthly temperature and salinity conditions were constructed by objective interpolation of all available hydrographic data in the vicinity of the boundary for 1995-2006. Alongshore transport on the inner shelf is driven by specifying the surface setup/setdown correlated with alongshelf winds implemented by J. Pringle following Schwing [1989]. The response of the Gulf of Maine to Scotian Shelf forcing is discussed in detail in the work of Pringle [2006].

\subsubsection{Bottom Friction Formulation}

[18] Bottom friction is implemented in the model using the quadratic drag law:

$$
\frac{\tau_{b}}{\rho_{0}}=-C_{d}\left|\mathbf{u}_{\mathbf{b}}\right| \mathbf{u}_{\mathbf{b}}
$$

with the drag coefficient is given by:

$$
\sqrt{C_{d}}=\frac{\kappa}{\ln \left(\frac{z}{z_{0}^{b}}\right)},
$$

where $\kappa$ is Von Karman's constant and $z$ is the distance from the seabed to the position where the velocity is calculated in the bottom-most layer in the model. The roughness length $z_{0}^{b}$ varies widely in the model domain. Measurements made on Georges Bank indicate a large range from 0.1 to $35 \mathrm{~mm}$ [Werner et al., 2003]. For the present FVCOM-GoM model, the roughness length is formulated using a depth-dependent criteria:

$$
z_{0}^{b}= \begin{cases}3 \times 10^{-3} & \text { if } D \leq 40 \\ 3 \times 10^{-3} \exp ^{-(D-40) / 8.8204} & \text { if } 40<D \leq 70 \\ 1 \times 10^{-4} \exp ^{-(D-70) / 13.0288} & \text { if } 70<D \leq 100 \\ 1 \times 10^{-5} & \text { if } D>100\end{cases}
$$

where $D$ is the depth of the water column in meters. This formulation is based on previous work investigating the impact of model bottom roughness parameterizations on $M_{2}$ tidal simulation in the Gulf of Maine/Georges Bank region [Chen et al., 2001].

\subsection{Initial Conditions and Dynamic Adjustment}

[19] Initial conditions are prescribed from monthly climatology fields derived from a composite database of observations spanning 40 years. It includes the BIO hydrographic database, the NMFS hydrographic database, the US GLOBEC/GB hydrographic database and the New England shelf-break hydrographic database created by C. Linder and G. Gawarkiewicz (WHOI). All data were preprocessed for quality control and then averaged onto a regular $10-\mathrm{km}$ resolution grid. An anisotropic interpolation scheme with increased weighting in the along-isobath direction was used to maintain the sharp cross-isobath gradient of water temperature and salinity at the shelf-break front in the initial fields.

[20] The model is spun up in three stages. First, the model is forced barotropically using only the tidal elevation from 1 November to 15 November 1994. In the second stage, hydrographic fields are added and the model integration is continued to 30 November 1994. From 1 December to 31 December 1994, the model is integrated with inclusion of winds, heat flux, and river flow. Starting from 1 January 1995, the model is integrated with all forcing, including freshwater transport, wind stress, heat flux, optimal interpolation of available hydrographic survey data, and nudging from SST, current meter, and open boundary hydrography. Tests made with longer spinup periods did not significantly alter the results.

\section{Wind Stress}

[21] Model-computed and observed wind stress statistics by season are provided in Table 1 . It should be noted that the $\mathrm{CMO}$ meteorological data were not used to nudge the MM5 model. Here the "fall" time frame spans from 4 August 1996 to 1 December 1996, "winter" from 1 December 1996 to 1 April 1997, and "spring" from 1 April 1997 to 14 June 1997 in accordance with previously published CMO results [Shearman and Lentz, 2003]. Computed and observed mean wind stress components for all seasons agree quite well. The model captures the seasonal trends in both the direction and magnitude of the mean. Mean model wind stress for all seasons is within $10 \%$ and orientation is within $19^{\circ}$.

[22] The model overpredicts the magnitude of the major axis of the wind stress variation in fall and spring by $25 \%$ and underpredicts the winter variability by $20 \%$. The major axis orientation is accurately predicted for all seasons with a maximum difference of $10^{\circ}$ occurring in spring. The fall variability is dominated by Hurricane Edouard which passed the mooring array on 2 September 1996 (Figure 3). Peak model-computed wind stress magnitude during Edouard was $1.8 \mathrm{~N} \mathrm{~m}^{-2}$, while peak observed was considerably lower at $1.2 \mathrm{~N} \mathrm{~m}^{-2}$. If the anomalous overprediction of Edouard is removed, the model is found to underpredict the fall variability by $15 \%$. Winter is marked by the continuous passage of frequent events, each of which appears to have peak strengths which are underpredicted in the model. In spring, the frequency decreases and several large events are notable in April. The first two storms (1 April and 18 April) are well represented by the MM5 hindcast while the third (23 April) is not resolved in the model. The NCEP data field needed to initialize the MM5 hindcast comprising 23 April was missing and the hindcast system subsequently recycled the NCEP initialization field from the previous forecast. To examine if the source of the discrepancy in the variability was due to differing bulk formula calculations, both raw computed and observed data was reprocessed with the COARE 3.0 flux algorithm [Fairall et al., 2003]. The recomputed wind stress statistics did not change appreciably. Given the difficulty of hindcasting weather over the ocean due to the paucity of observations available for assimilation, we feel the model data comparison results presented here are reasonable.

\section{Hydrography}

[23] Comparison of computed and observed hydrographic data at the central CMOC mooring site is shown in Figure 4. The structure and magnitude of the temperature fields are in 
Table 1. Subtidal Wind Stress Statistics at CMO Central Mooring Site

\begin{tabular}{|c|c|c|c|c|c|}
\hline \multirow[b]{2}{*}{$\underline{\text { Season }}$} & \multicolumn{2}{|c|}{ Mean } & \multicolumn{3}{|c|}{ Principal Axes } \\
\hline & Magnitude $\left(\mathrm{N} \mathrm{m}^{-2}\right)$ & Direction $\left({ }^{\circ} \mathrm{T}\right)$ & Major Axis $\left(\mathrm{N} \mathrm{m}^{-2}\right)$ & Minor Axis $\left(\mathrm{N} \mathrm{m}^{-2}\right)$ & Orientation $\left({ }^{\circ} \mathrm{T}\right)$ \\
\hline \multicolumn{6}{|c|}{ CMO-Observed } \\
\hline Full & 0.034 & 121 & 0.11 & 0.11 & 85 \\
\hline Fall & 0.026 & 157 & 0.11 & 0.08 & 173 \\
\hline Winter & 0.057 & 109 & 0.15 & 0.12 & 95 \\
\hline Spring & 0.025 & 110 & 0.10 & 0.07 & 14 \\
\hline \multicolumn{6}{|c|}{ MM5-Computed } \\
\hline Full & 0.034 & 122 & 0.12 & 0.10 & 6 \\
\hline Fall & 0.027 & 169 & 0.14 & 0.07 & 176 \\
\hline Winter & 0.059 & 99 & 0.12 & 0.09 & 102 \\
\hline Spring & 0.023 & 139 & 0.13 & 0.07 & 24 \\
\hline
\end{tabular}

close agreement. The observations show a deeper thermocline in early fall and late spring. Periodic motions of the shelf slope front in January and February caused noticeable temperature inversions in the observed temperature field which are weakly present in the model results.

[24] The model-computed and observed salinity fields are in reasonable agreement. Average model and observed surface salinity during the CMO period are 32.05 and $31.81 \mathrm{ppt}$, respectively. The halocline depth and evolution is well represented in the model in early winter and late spring. Shelf slope front foot motion is strongly evident in the observed fields in winter but only weakly present in the model. Cross-shelf displacement of the foot is $\sim 10 \mathrm{~km}$ in the model-computed fields during upwelling- and downwelling-favorable wind events (not shown). This is at the low end of the typical range of $10-20 \mathrm{~km}$ found in previous field studies [Houghton et al., 1988]. This may partially explain the reduction in the salinity fluctuations, although the position and strength of the front will also play a role. For changes over larger timescales, the model fails to capture the magnitude of the increased near-bottom salinity in late December and January but does resolve the surge in late February-early March. The resolution of modelcomputed near-bottom salinity may be influenced by the truncation of bathymetry off the shelf to $300 \mathrm{~m}$, an issue that will be addressed in future work using models retaining full bathymetry. The largest discrepancy in surface salinity occurs in May 1997. During this period, anomalously eastward wind stress carried a moderately sized Connecticut River spring discharge out onto the NES to the CMO moored array area [Lentz et al., 2003]. Due to the strength of the westward flowing model-computed mean currents in spring, the Connecticut River plume is not able to reach the CMO location. This issue is discussed in more detail in section 8.2. While there is reasonable agreement in surface densities, the near-bottom density field reflects the discrepancies in the salinity field.

[25] The bottom panel in Figure 4 shows the log of the subtidal turbulent vertical diffusivity $\left(K_{m}\right)$ from the model. The strong mixing event seen in early September is caused by the passage of Hurricane Edouard (white line). Mixing in the fall and winter is confined to surface and bottom
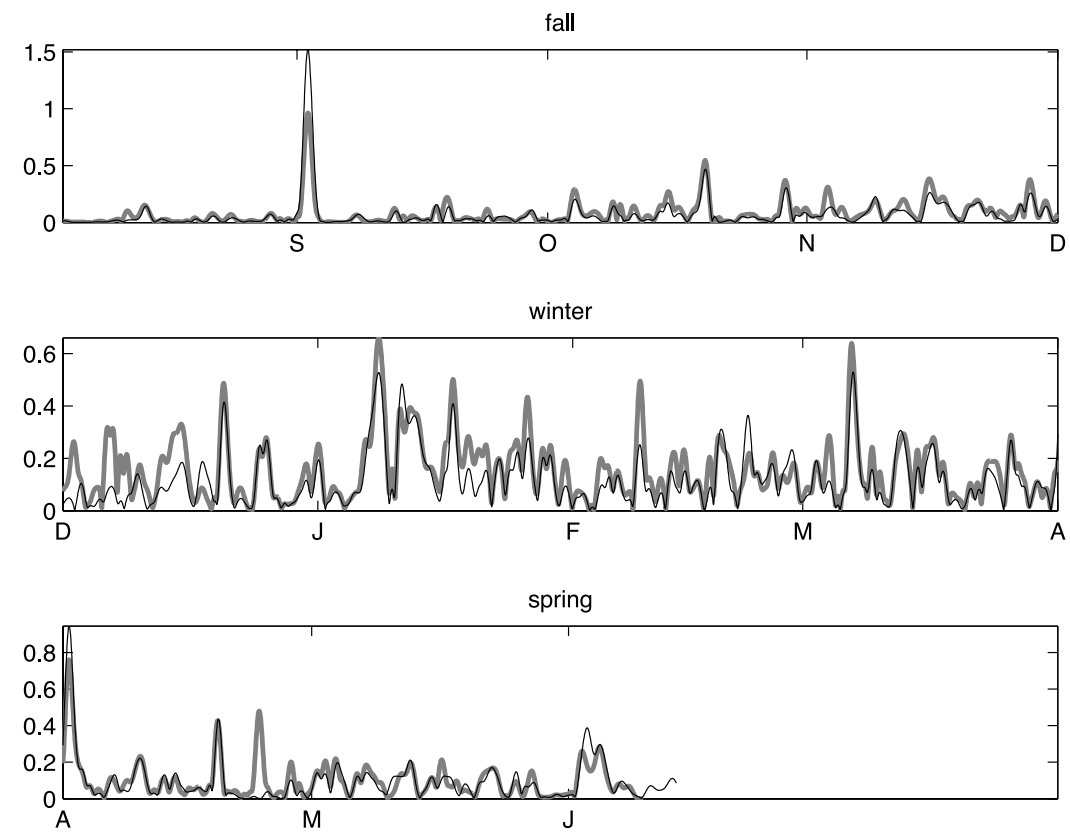

Figure 3. CMO-Observed (thick shaded line) and MM5-Computed (thin black line) subtidal wind stress magnitude $\left(\mathrm{N} \mathrm{m}^{-2}\right)$ at the CMO Central Mooring Site. 

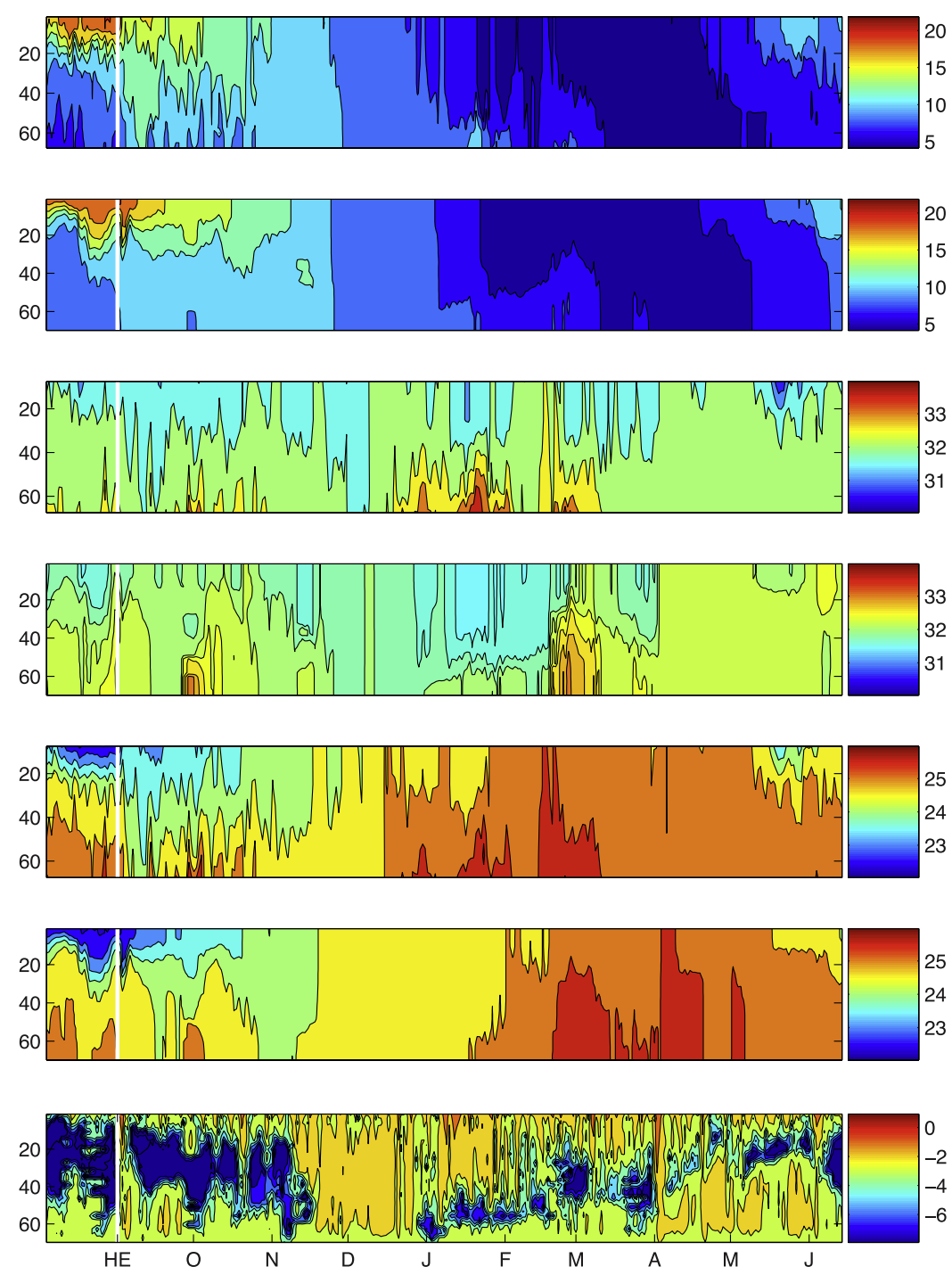

Figure 4. Hydrography at CMO Central Site: (top to bottom) temperature $\left({ }^{\circ} \mathrm{C}\right)$ [obs/model], salinity (ppt) [obs/model], $\sigma_{t}\left(\mathrm{~kg} \mathrm{~m}^{-3}\right)$ [obs/model], and $\log _{10}\left(K_{m}\right)$ [model only]. White line: Hurricane Edouard.

boundary layers. In early winter, the water column is well mixed, but in late winter, intermittent movements of the shelf slope front foot build lower water column stratification and inhibit mixing. This continues until spring when surface warming and freshening rebuild the surface stratification, isolating the surface and bottom boundary layers.

[26] A comparison of observed and computed stratification (surface to near-bottom difference) of temperature, salinity, and density is shown in Figure 5. The distinct annual cycle is evident, characteristic of midlatitude shelves. Light winds, strong heat flux, and the late spring/ early summer arrival of remote sources of buoyancy combine to build summer stratification. This stratification is broken down during strong wind events in the fall and early winter. During winter and early spring, periodic restratification occurs, generated by motion of the foot of the shelf slope front. This is most evident in the salinity signal. Similar foot motion is evident in the model results, although weaker in magnitude. The model temperature stratification follows closely that of the observed, although it is considerably smoothed.
[27] The passage of Hurricane Edouard (dashed vertical line) caused a rapid decrease in bottom-surface density difference which is not evident in the model trace even in the presence of strong mixing (Figure 4). Observed potential density difference directly before the storm (yd 244) was $2.8 \mathrm{~kg} \mathrm{~m}^{-3}$ and several days after (yd 248) had decreased threefold to $0.9 \mathrm{~kg} \mathrm{~m}^{-3}$ due to the intense mixing [MacKinnon and Gregg, 2002]. In the model, there is an increase in the density difference from $1.5 \mathrm{~kg} \mathrm{~m}^{-3}$ to $2.1 \mathrm{~kg}$ $\mathrm{m}^{-3}$ during this same period, followed by a decline to prestorm levels over several days (Figure 4).

[28] The observed breakdown of stratification in fall is seen to occur during discrete events, including Hurricane Edouard. Analysis by Lentz et al. [2003] of the major wind events occurring during this period and the subsequent modifications to hydrography and low-frequency circulation found that during the four discrete drops in stratification, the common factor was relatively large westward wind stress. While the model tracks the general breakdown of stratification, there is little evidence of these discrete shifts, with the possible exception of a noticeable drop in density 

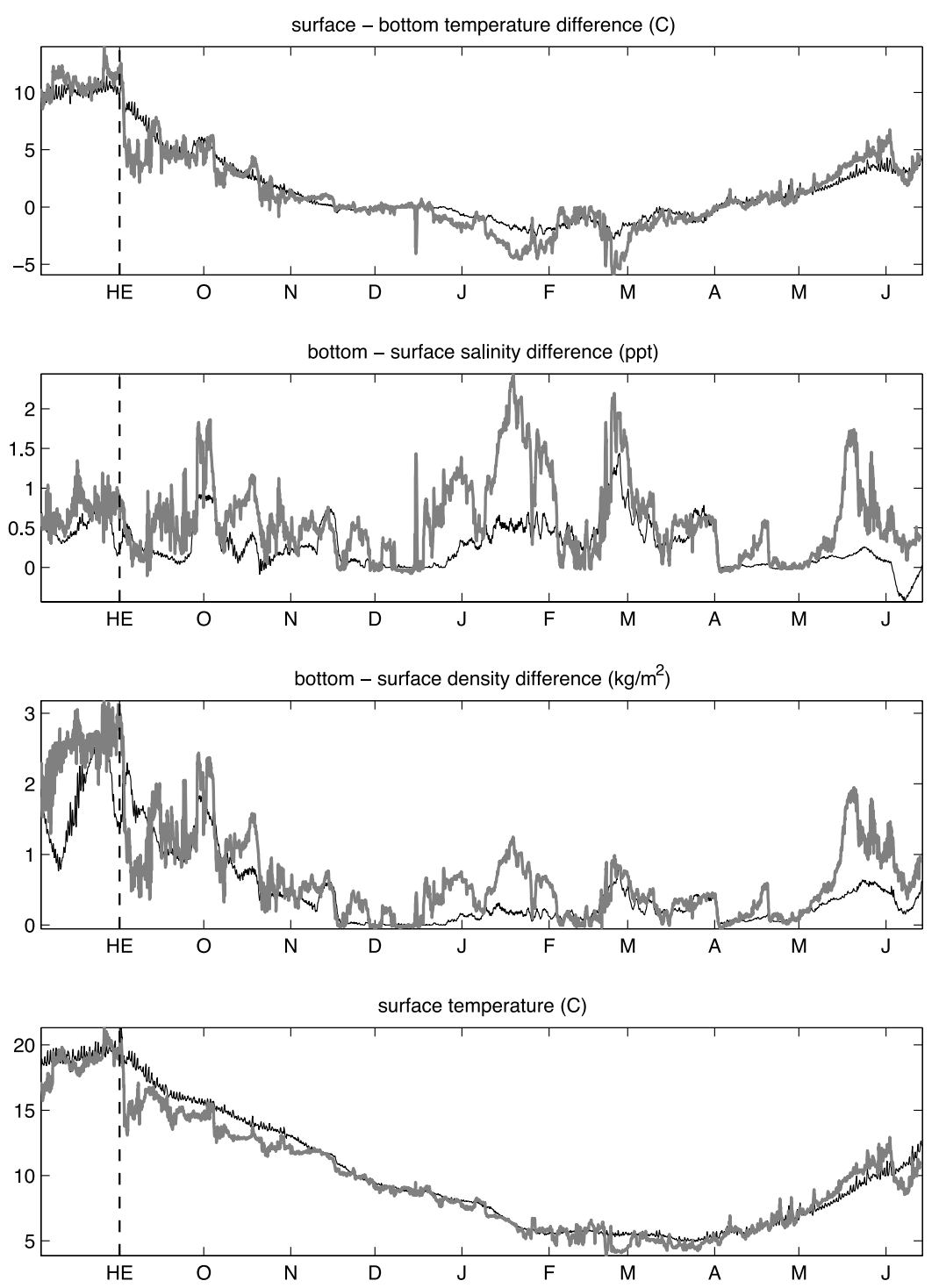

Figure 5. Observed (thick shaded line) and FVCOM-computed (thin black line) stratification and surface temperature at CMOC Site (dashed line: Hurricane Edouard).

difference following the 18 October storm, the last of the four strong westward wind stress events in fall 1996. The correlation with westward along-coast wind stress is thought to derive from enhanced mixing due to a decrease in stratification brought on by downwelling or through an increase in vertical shear by positive combination of winddriven and horizontal density-driven components [Lentz et al., 2003].

[29] The ability of the model to reproduce the seasonal cycle of stratification without resolving the discrete breakdown following large storms originates from the method used to assimilate the observed SST data. During periods of cloud coverage, the processed satellite-derived SST reverts back to climatological values which will not include the surface cooling associated with the passage of large storms. A model experiment was conducted using no SST assimilation for a short period containing Hurricane Edouard. The model produced much more reasonable sea surface temperature and stratification histories. A more thorough discus- sion of the impact of the SST assimilation method is provided in section 8 .

\section{Mean Currents}

[30] The mean currents are described in terms of their along- $\left(u^{\prime}\right)$ and cross- $\left(v^{\prime}\right)$ isobath components. The isobath angle is defined as a line running along $110 / 290^{\circ} \mathrm{T}$ in accordance with $\mathrm{CMO}$ publication convention [Shearman and Lentz, 2003]. Positive along-isobath flow is roughly eastward and positive cross-isobath flow is northward, directed onshore. Measurement uncertainty in the observed currents was $\pm 2 \mathrm{~cm} \mathrm{~s}^{-1}$ [Shearman and Lentz, 2003] including unknown biases and thus could be considered an upper bound on the error in the observed mean velocity components. Mean model-computed currents averaged over the CMO period are westward and offshore at all depths (Table 2, Figure 6). Model currents at all depths are stronger than observed by roughly $20 \%$. Both observed and model currents exhibit clockwise rotation between surface and 
Table 2. Subtidal Current Statistics at CMO Central Mooring Site

\begin{tabular}{|c|c|c|c|c|c|c|}
\hline \multirow[b]{2}{*}{ Data Set } & \multicolumn{2}{|c|}{ Mean } & \multicolumn{4}{|c|}{ Principal Axes } \\
\hline & Magnitude $\left(\mathrm{cm} \mathrm{s}^{-1}\right)$ & Direction $\left({ }^{\circ} \mathrm{T}\right)$ & Major Axis $\left(\mathrm{cm} \mathrm{s}^{-1}\right)$ & Minor Axis $\left(\mathrm{cm} \mathrm{s}^{-1}\right)$ & Major/Minor (-) & Orientation $\left({ }^{\circ} \mathrm{T}\right)$ \\
\hline \multicolumn{7}{|c|}{ Surface } \\
\hline Observed & 8.66 & 246 & 13.32 & 6.91 & 1.93 & 109 \\
\hline Model & 11.85 & 273 & 11.66 & 6.43 & 1.81 & 111 \\
\hline \multicolumn{7}{|c|}{$30 \mathrm{~m}$} \\
\hline Observed & 8.40 & 275 & 11.13 & 3.87 & 2.88 & 111 \\
\hline Model & 10.76 & 284 & 7.81 & 2.72 & 2.88 & 113 \\
\hline \multicolumn{7}{|c|}{$60 \mathrm{~m}$} \\
\hline Observed & 5.35 & 270 & 10.12 & 3.79 & 2.76 & 99 \\
\hline Model & 6.21 & 282 & 6.72 & 2.50 & 2.69 & 103 \\
\hline \multicolumn{7}{|c|}{ Vertical Average } \\
\hline Observed & 7.74 & 270 & 10.97 & 3.60 & 3.04 & 109 \\
\hline Model & 9.40 & 281 & 7.74 & 2.53 & 3.06 & 110 \\
\hline
\end{tabular}

mid-depth. Seasonal mean currents show good prediction of the strong fall current, and average winter current but the spring current magnitude is largely overpredicted by the model at all depths (Figure 6). While this may be partly due to poor resolution of the 23 April storm in the model forcing (section 3), the surface current time history (Figure 7) indicates that the discrepancy continues through the entire month of May, an anomalous period in which the observed current flows primarily eastward. This indicates that inadequate resolution of some remote forcing is more likely the cause for the overprediction of spring currents. This issue is further elaborated in section 8 .

[31] Contribution of tidal rectification to mean flow at the CMOC site is small but nonnegligible. Tidal currents on the NES are complex due to the location being a transition between the resonant Gulf of Maine and the Mid-Atlantic Bight systems [Shearman and Lentz, 2004].
When FVCOM-GoM was run in a barotropic simulation forced only by prescribed tidal elevation at the open boundary, the mean transport at the CMOC site was found to be approximately $1 \mathrm{~cm} \mathrm{~s}^{-1}$ westward, accounting for approximately $20 \%$ of the mean current.

[32] Mean barotropic (BT) and baroclinic (BC) geostrophic along- and cross-isobath velocity components are computed using the relations;

$$
\begin{gathered}
\left(u_{B T}^{g}, v_{B T}^{g}\right)=\frac{g}{f}\left(-\frac{\partial \eta}{\partial y}, \frac{\partial \eta}{\partial x}\right) \\
\left(u_{B C}^{g}, v_{B C}^{g}\right)=\frac{g}{\rho_{0} f}\left(-\frac{\partial B}{\partial y}, \frac{\partial B}{\partial x}\right)
\end{gathered}
$$
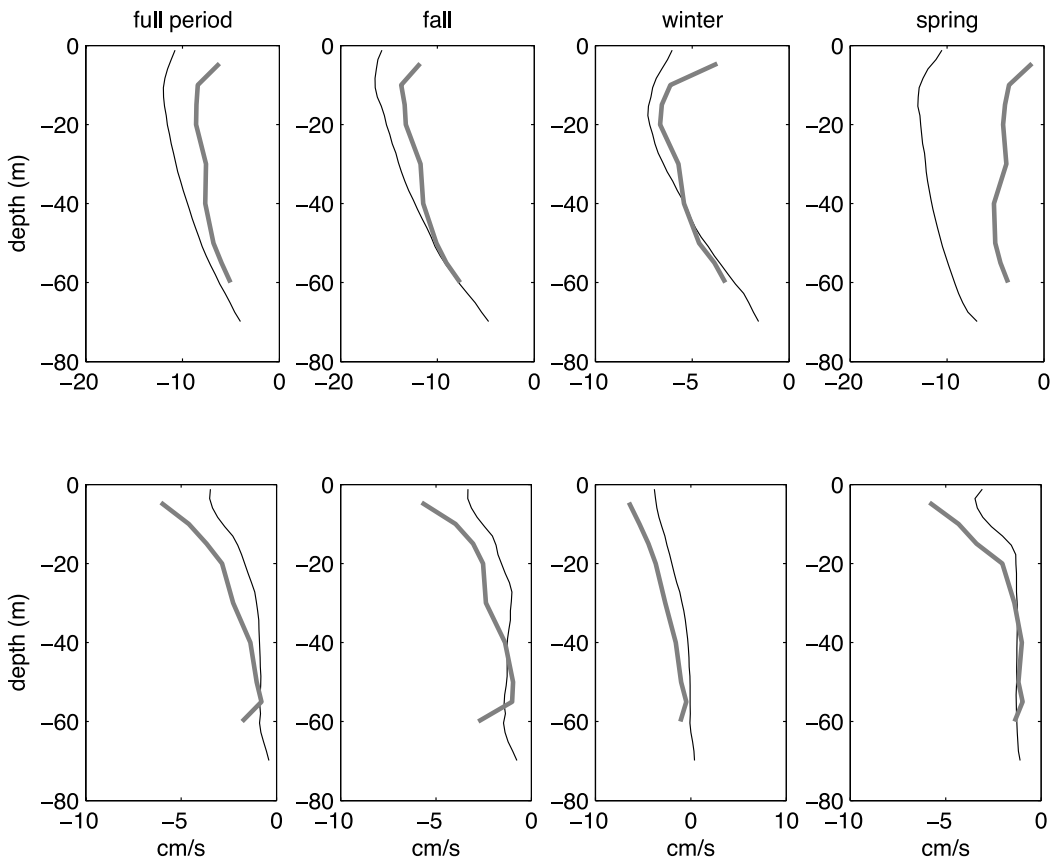

Figure 6. Profiles of Observed (thick shaded line) and FVCOM-computed (thin black line) mean velocity at the CMOC Site. (top) Along-isobath. (bottom) Cross-isobath. 

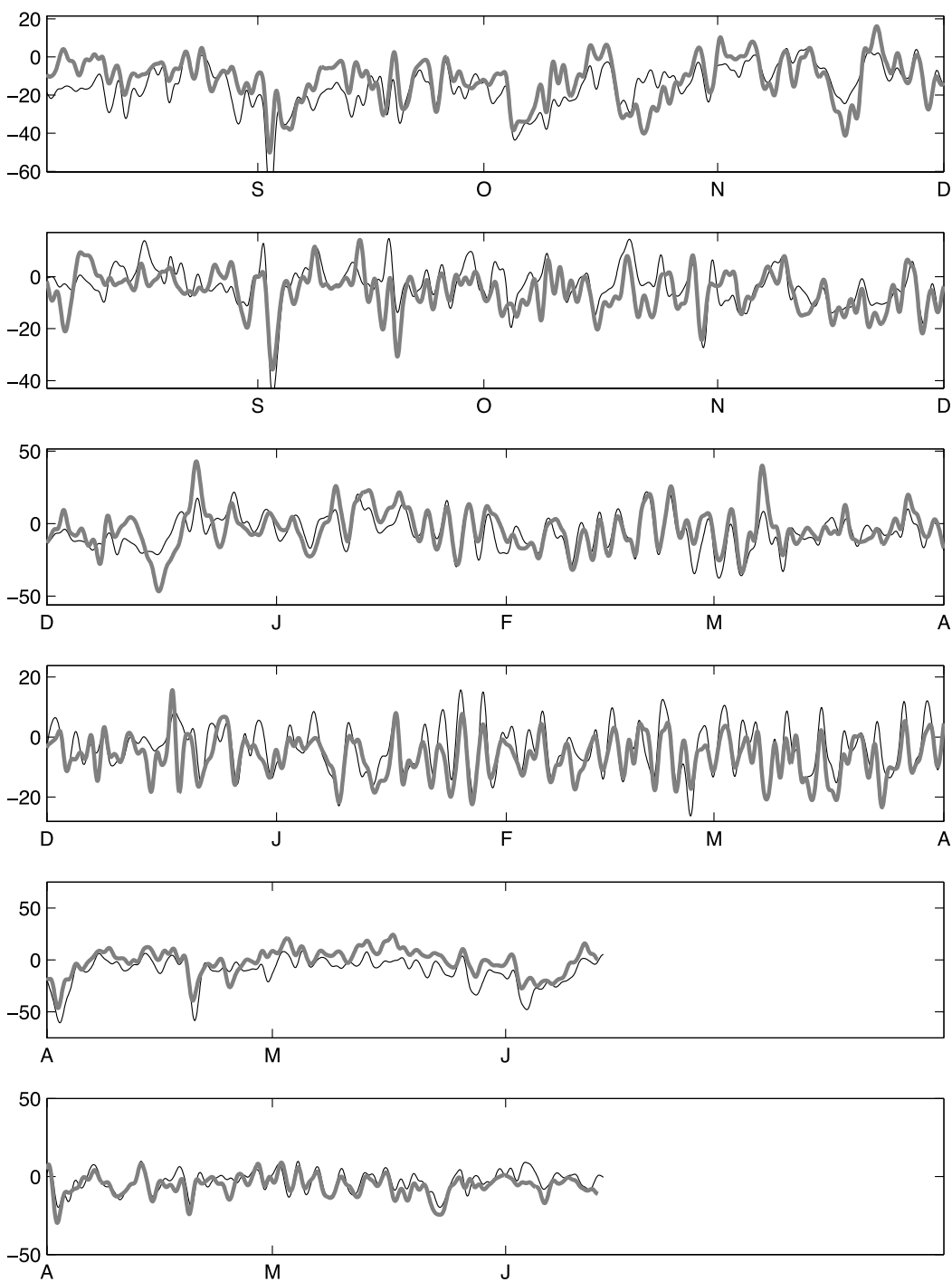

Figure 7. Observed (thick shaded line) and FVCOM-computed (thin black line) subtidal along-isobath (top) and cross-isobath (bottom) surface currents at the CMO Central Site.

where the pressure at depth $z$ is

$$
B=g \int_{z}^{\eta} \rho d z,
$$

$g$ is the gravitational acceleration $\left(9.81 \mathrm{~m} \mathrm{~s}^{-2}\right)$ and $f$ is the Coriolis parameter at the $\mathrm{CMO}$ Central mooring site $\left(9.44 \times 10^{-5} \mathrm{~s}^{-1}\right)$.

[33] Due to drift in long-term bottom pressure observations, reliable calculations of observed BT geostrophic currents could not be made and previous analysis relied on an assumption of geostrophy at a depth of $50 \mathrm{~m}$ to infer the BT geostrophic currents [Shearman and Lentz, 2003]. Figure 8 shows the observed and compute mean velocity components for the $\mathrm{CMO}$ period. Model and observed along-isobath baroclinic geostrophic profiles compare well. Cross-isobath geostrophic flow is northward at all depths, but the magnitude of the observed flow is larger. Observed along-isobath ageostrophic flow is eastward above $50-\mathrm{m}$ depth and zero at $50 \mathrm{~m}$ (by definition). Model-computed ageostrophic along-isobath flow is eastward above $10 \mathrm{~m}$ and westward below. Cross-isobath ageostrophic flow for both model and observed flowfields is offshore at all depths except very near the bottom where weak shoreward ageostrophic flow is present in both results.

[34] One strength of a model is that the barotropic geostrophic pressure gradient can be readily calculated. In this case, if the observed geostrophic flow is recalculated using the model-computed barotropic geostrophic flow, instead of the assumption of geostrophy at $50 \mathrm{~m}$, the result is a strong eastward ageostrophic along-isobath flow, with unrealistic surface magnitude exceeding $6 \mathrm{~cm} \mathrm{~s}^{-1}$. Given the good comparison of model-computed and observed geostrophic baroclinic flow and wind-forcing, it is likely that the strong model-computed barotropic geostrophic forcing may be the source of the overprediction of modelcomputed total along-isobath current magnitude.

\section{Low-Frequency Current Variability}

[35] Both model and observed flow velocities were lowpass filtered with a 33-hour cutoff to compare the variability 

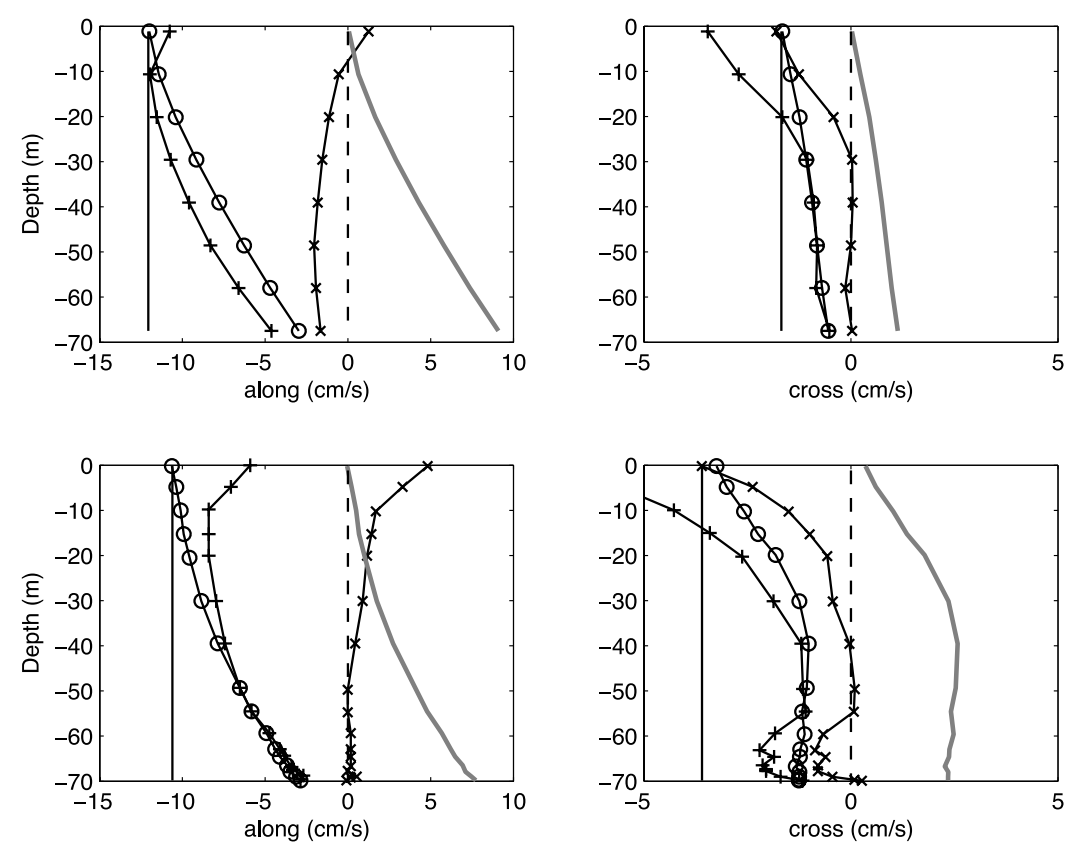

Figure 8. Profiles of computed (top) and observed (bottom) mean subtidal velocity components for full $\mathrm{CMO}$ period at the CMOC Site. Components: barotropic geostrophic (thin black line), baroclinic geostrophic (thick shaded line), total geostrophic (circles), total (pluses), and ageostrophic (crosses). Model results have been sparsified to improve figure clarity.

of the low-frequency current. The along- and cross-isobath low-frequency surface velocities by season are shown in Figure 7. The model captures well the magnitude of the wind-driven surface flow, particularly during midwintertime (February). The surface currents generated by Hurricane Edouard (early September) are stronger than observed currents which is consistent with the overprediction of the wind stress associated with the hurricane in the meteorological model (section 3). There are several large measured current events that are not evident in the model fields, for example, the fluctuation that occurred mid-December 1996. This signal correlates with a strong movement of the shelf slope front as observed in the bottom temperature signal in the CMOC data. Overall, the correlation of model and measured subtidal along-isobath currents for the CMO period is quite strong at the surface $(0.74, \pm 0.01, p<0.01)$ but weaker at $30 \mathrm{~m}(0.57 \pm 0.05, p<0.01)$ and $60 \mathrm{~m}(0.56 \pm$ $0.015, p<0.01)$.

[36] The subtidal variability statistics for model and observed currents at the CMOC site are listed in Table 2. For both data sets, the major axis is of the same order as the mean current, is oriented roughly along-isobath (within $5^{\circ}$ ) and is roughly twice the magnitude of the weaker crossisobath variability. Variability decreases with depth. Seasonal variability was found to be strongly influenced by the definition of seasonal time frames and thus only results for the full CMO period are shown here. While the model predicts a decreasing variability with depth and a maximum in the ellipticity (ratio of major and minor axes) at middepth, the magnitudes of the major and minor axes are underpredicted at all depths by $10 \%$ to $30 \%$. The orientation of the major axis in both model-computed and observed results is within $5^{\circ}$ of the local isobath angle $\left(110^{\circ} \mathrm{T}\right)$ at all depths.
[37] Model and observed bottom stress statistics are presented in Table 3. Observed quantities are adapted from Table 2 of Shearman and Lentz [2003]. Mean magnitude in the model computed bottom stress is significantly larger during all season. Model-computed and observed mean direction are within $6^{\circ}$ for all season. The major axis of the model-computed and observed bottom stress variability is in excellent agreement in fall and winter but in spring the model overestimates the variability by a factor of 2 . Agreement in the orientation of the major axis is within $12^{\circ}$. Observed bottom stress is significantly lower than wind stress in all seasons (Table 1) while the model bottom stress is closer in magnitude to the wind stress, particularly in the spring. The low values of the observed bottom stress were noted by Shearman and Lentz [2003]. The authors explain that the CMO mooring array was located in a region of the NES known as the "mud patch" for a prevalently muddy bottom type and associated reduced bottom stress. Bottom roughness in the model does not explicitly account for the spatial distribution of the substrate and thus may result in an overprediction of bottom stress in such regions.

\section{Correlation With Wind Forcing}

[38] Subtidal current variablity on the NES is dominated by wind-forcing [Beardsley et al., 1985; Brown et al., 1985; Shearman and Lentz, 2003]. The response of the shelf currents to wind-forcing from various angles is dependent on stratification, regional scale shelf geometry, and bottom friction. Previous work [Beardsley et al., 1985; Shearman and Lentz, 2003] found that the response was most strongly correlated with wind-forcing that was rotated relative to the local isobath direction. The angle for maximum response was found to be $45^{\circ} \mathrm{T}$ in the analysis of Shearman et al. and 
Table 3. Subtidal Bottom Stress Statistics at Central Site

\begin{tabular}{|c|c|c|c|c|c|}
\hline Season & Magnitude $\left(\mathrm{N} \mathrm{m}^{-2}\right)$ & Angle $\left({ }^{\circ} \mathrm{T}\right)$ & Major Axis $\left(\mathrm{N} \mathrm{m}^{-2}\right)$ & Minor Axis $\left(\mathrm{N} \mathrm{m}^{-2}\right)$ & Orientation $\left({ }^{\circ} \mathrm{T}\right)$ \\
\hline \multicolumn{6}{|c|}{ CMO-Observed } \\
\hline Model & 0.005 & 110 & 0.017 & 0.006 & 94 \\
\hline Fall & 0.006 & 103 & 0.015 & 0.007 & 89 \\
\hline Winter & 0.003 & 125 & 0.019 & 0.006 & 99 \\
\hline Spring & 0.004 & 107 & 0.015 & 0.003 & 91 \\
\hline \multicolumn{6}{|c|}{ FVCOM-Computed } \\
\hline Full & 0.014 & 104 & 0.024 & 0.007 & 100 \\
\hline Fall & 0.017 & 101 & 0.017 & 0.006 & 101 \\
\hline Wint & 0.006 & 121 & 0.017 & 0.008 & 98 \\
\hline Spring & 0.023 & 101 & 0.035 & 0.006 & 101 \\
\hline
\end{tabular}

$65^{\circ} \mathrm{T}$ in the analysis of Beardsley et al. These angles correspond roughly with an along-coast direction for southern New England if considered over a large scale and thus is congruent with theory of coastal setup/setdown presented by Allen [1980].

[39] Correlation of the along-isobath vertically averaged subtidal flow with wind angle and lag is shown in Figure 9 for both model and observed responses. Correlations patterns are quite similar and display important seasonal distinctions. The model captures the broader peaks in spring and fall and the stronger, narrow peak of winter. The modelcomputed and observed correlation for a range of wind angles at a 10-hr lag (Figure 10) is found to be in good agreement for all seasons. In the fall, the angle of maximum correlation is around $60^{\circ} \mathrm{T}$. In winter, the peak response occurs around $45^{\circ} \mathrm{T}$. In spring, the peak correlation is the highest and response is the flattest and most symmetric. A strong correlation in both model-computed and observed quantities exists for wind angles from $0^{\circ} \mathrm{T}$ to $50^{\circ} \mathrm{T}$, but the actual peak occurs near $45^{\circ} \mathrm{T}$.
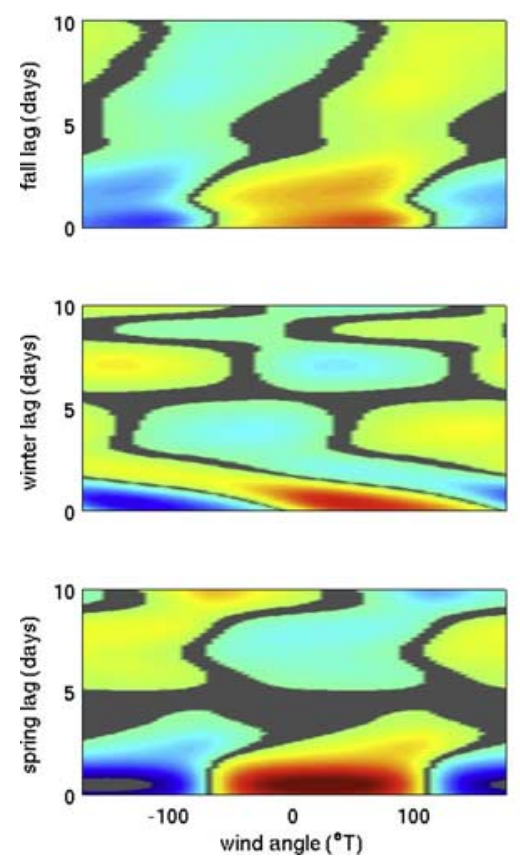

[40] For a wind direction of $45^{\circ} \mathrm{T}$, the model is able to capture the peak lag of $\sim 10$ hours in the winter and spring (Figure 11). This is in agreement with Beardsley et al. [1985], who found peak correlation at lags of 6-12 hours. In the fall, peak correlation occurs at a 44-hr lag, which is present as a notable secondary peak in the observed correlation. The winter response for both model and observed results is complex due to the persistence of high-frequency storms during this period which are separated by intervals that are shorter than the lags of interest (several days).

\section{Discussion}

\subsection{SST Assimilation}

[41] In the current FVCOM-GoM system, the computed sea surface temperature (SST) is nudged toward the observed state as described in section 2.2.4. The satellitederived observed SST data is processed using data analysis techniques to fill the gaps created by cloud cover by reverting to climatology. As cloud coverage is frequently associated with storms, the model tends to follow climatology during
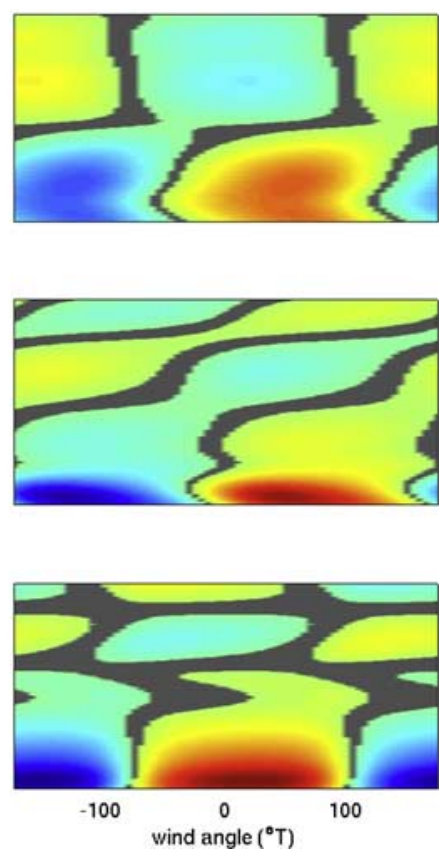

Figure 9. Correlation between observed (left) and model (right) vertically averaged along isobath currents with wind direction. Range: $[-0.8$ (blue), 0.8 (red), correlation not significant, $P>0.05$ (gray)]. 

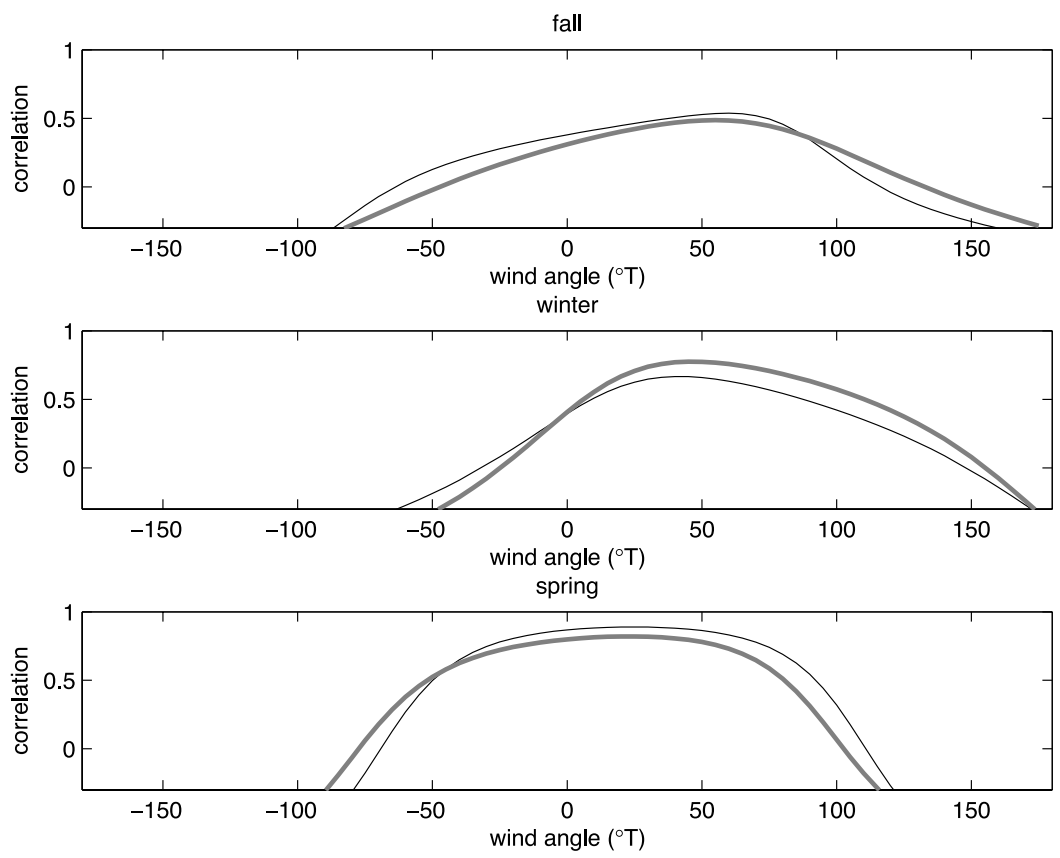

Figure 10. Observed (thick shaded line) and FVCOM-computed (thin black line) along-isobath vertically averaged current correlation with wind at 10 -hr lag (values for significantly correlated time series only, $P<0.05$ ).

these periods rather than true surface cooling. This is particularly evident during the period following Hurricane Edouard when model-computed stratification was found to increase slightly. To examine the impact of the SST nudging as a potential source of the incorrect storm response in the model, a 2-week model run encompassing the time of passage of Hurricane Edouard was made using no SST data assimilation. Figure 12 shows model SST for runs with and without SST assimilation as well as the SST measured during CMO and the processed satellite-derived SST. For the case with no assimilation, the model resolves very well the rapid surface cooling and subsequent warming. This experiment implies that the model is able to resolve the discrete drops in stratification better if the
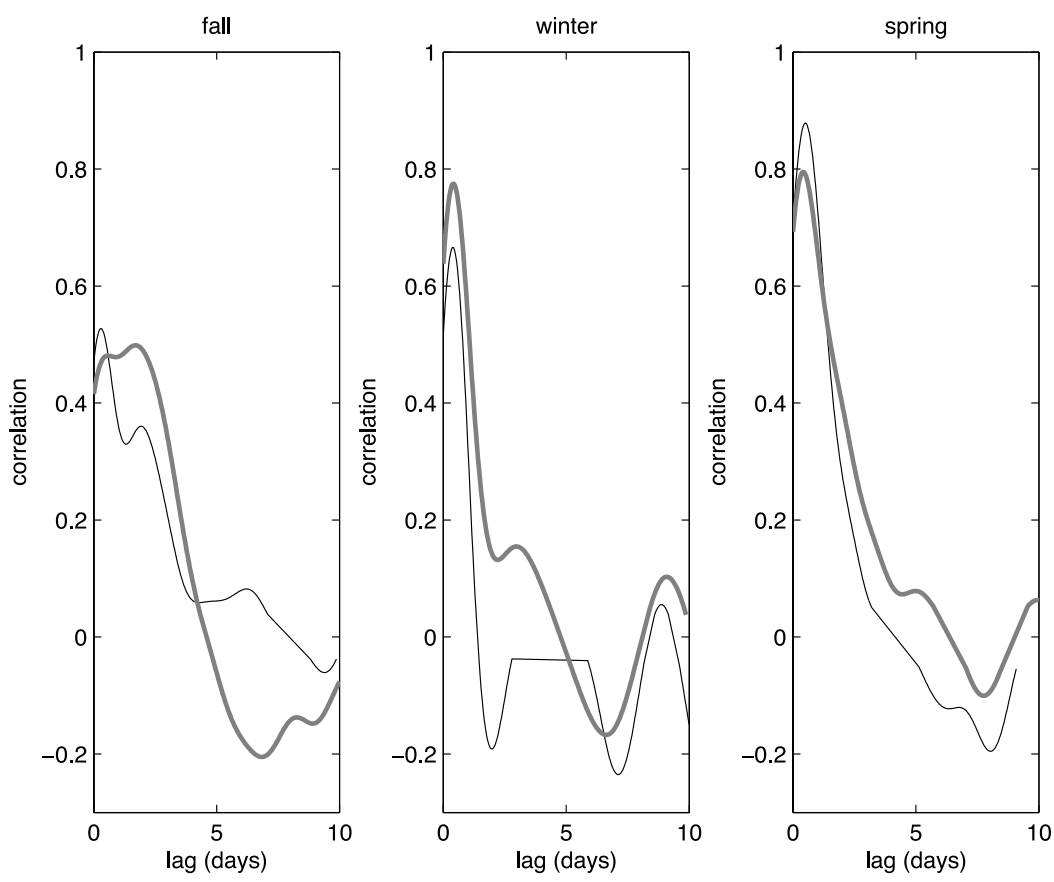

Figure 11. Observed (thick shaded line) and FVCOM-computed (thin black line) along-isobath vertically averaged current correlation with wind at $45^{\circ} \mathrm{T}$, (values for significantly correlated time series only, $P<0.05)$. 


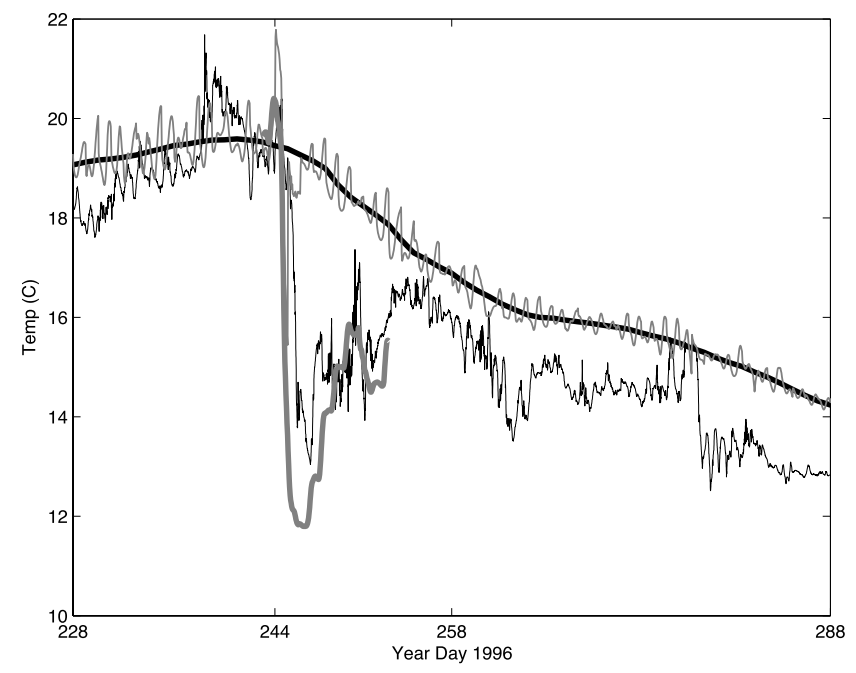

Figure 12. Sea surface temperature during the passage of Hurricane Edouard computed using model runs with SST data assimilation (thin shaded line) and without (thick shaded line). Processed satellite derived SST data (thick black line) and observed SST from the CMO mooring (thin black line) shown for reference.

nudging coefficient is reduced considerably, particularly during times when cloud coverage makes remote sensing data unavailable.

[42] In addition to issues relating to the nudging relaxation rate, the general method of correcting model temperatures using SST assimilation can be problematic for regions like the Gulf of Maine where temperature inversions are commonly found. As noted by Pringle [2006], in a noninverted system, the utilization of SST assimilation tends to correct errors in the extant of the surface mixed layer. A mixed layer which is too deep will tend to produce model temperatures which are cooler than observed, and the SST nudging will act to reduce mixing. If the mixed layer is too shallow, the opposite mechanism will act to increase mixing. For a system with inverted temperature, the feedback will not result in a correction. The technique used in FVCOM-GoM uses daily-averaged values to nudge the SST and thus would not include this incorrect feedback on the diurnal mixed layer depth variation. However, for long-term mixed layer variation, the problem remains. While the spatial and temporal coverage of remotely sensed SST renders it extremely useful for the improvement of model skill, work on improved and dynamically appropriate methods of incorporating these data must continue.

\subsection{Connecticut River Plume}

[43] Low salinity water was observed at the CMO central mooring array during May, 1997, reaching a minimum at the surface of $30.7 \mathrm{ppt}$ on May 20. Analysis by Lentz et al. [2003] found the source of this fresh layer to be the southern New England rivers on the Connecticut and Rhode Island coasts. Anomalous NE winds in May combined with higher than normal discharge, resulting in a fresh surface layer that stretched out to the CMO site. While the model-computed salinity at the CMO central site shows a drop in May, the minimum surface salinity, reached on May 22 is $32.0 \mathrm{ppt}$, considerably higher than observed. This drop is not likely linked to the southern New England rivers. Surface salinity from previous model runs which did not include southern New England river discharge are nearly identical to the present model-computed results (not shown). An examination of the evolution of the surface salinity shows that the plume extends properly from the edge of Long Island Sound toward the southwest (Figure 13) during the first few weeks of May in accordance with CMO findings [Lentz et al., 2003]. However, the closest approach of the 31 ppt salinity water to the CMO central site is $45 \mathrm{~km}$, attained on 19 May.

[44] There are several possibilities why the plume was not able to extend out as far as the CMO site. Errors in the meteorological model-computed winds could diminish the southwestward Ekman transport, thought to be the critical
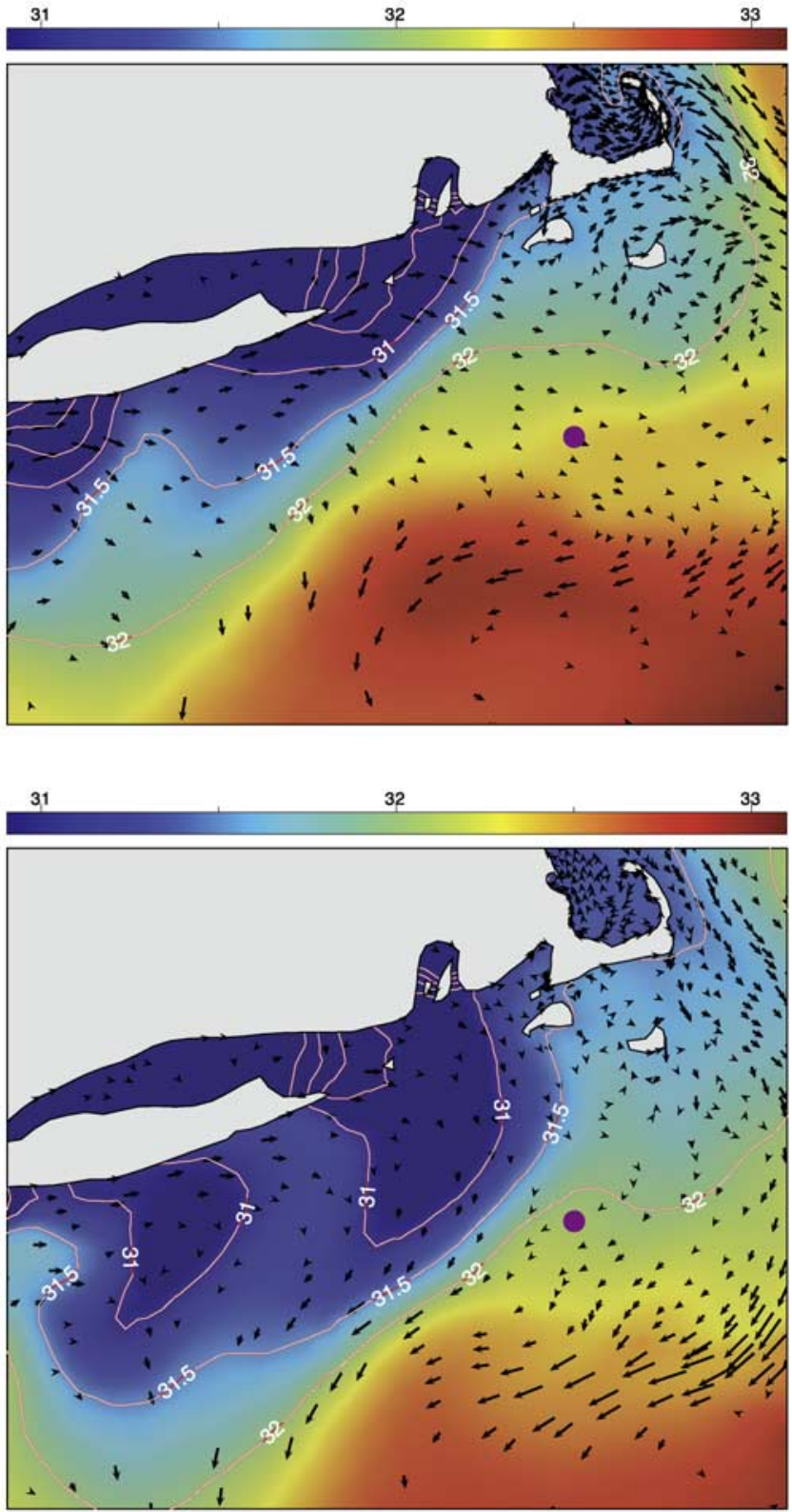

Figure 13. Model-computed surface salinity (ppt) on 1 May 1997 (top) and on 19 May 1997 (bottom). CMO central mooring location (filled circle). 


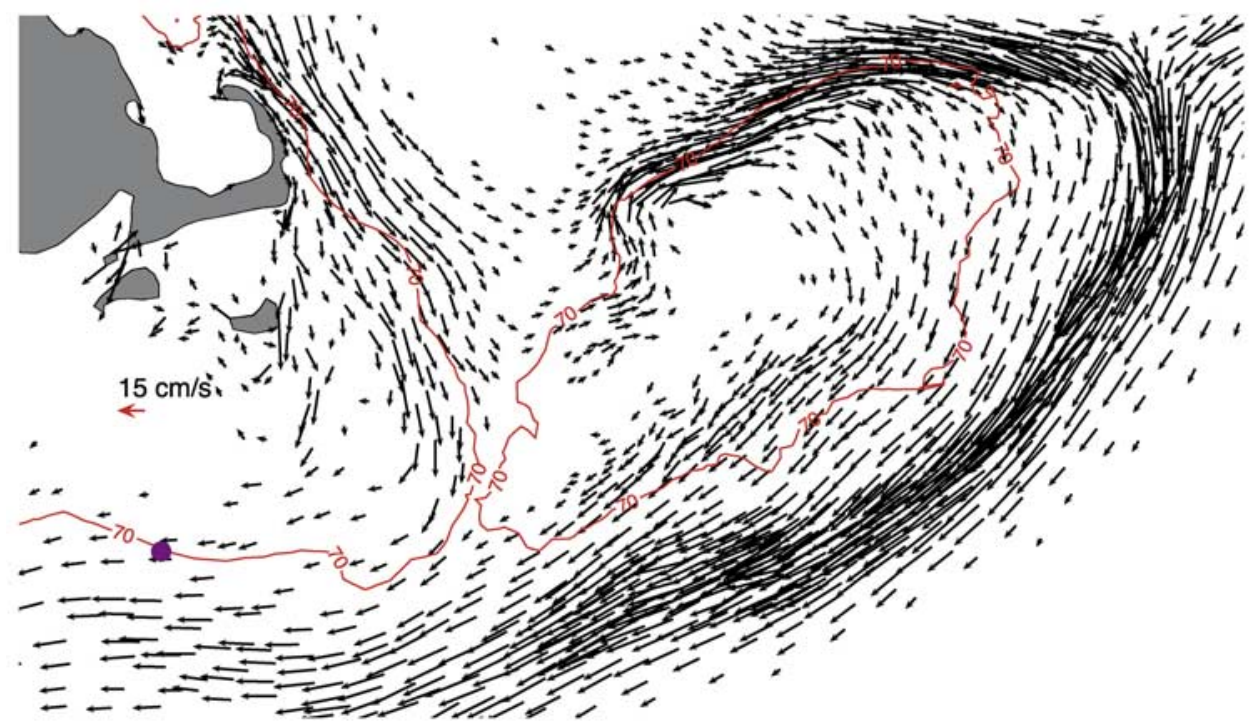

Figure 14. Mean surface subtidal model velocity over CMO period on Georges Bank and the eastern New England Shelf. Vectors are sparsified by a factor of 3 and rendered only where the magnitude exceeds $5 \mathrm{~cm} \mathrm{~s}^{-1}$. The current magnitude at the CMOC site is $11.4 \mathrm{~cm} \mathrm{~s}^{-1}$. For comparison, the maximum current magnitude on the Northeast Peak of GB is $\sim 38 \mathrm{~cm} \mathrm{~s}^{-1}$. The pattern and magnitude on GB compares well with previous comprehensive modeling studies [Lynch and Naimie, 1993].

driver of the plume transport [Lentz et al., 2003]. However, the model-computed wind stress in spring was found to be quite accurate (Figure 3, Table 1). A second possibility is that the cross-shelf velocity of the plume was reduced by underprediction of horizontal diffusion in the model. Model-observation comparisons of dye tracer studies on Georges Bank [Chen et al., 2008] with FVCOM indicated that low horizontal diffusion could lead to a reduction of cross-isobath dye motion relative to measurements. A third and most likely reason the plume did not extend to the CMO central site is that the magnitude of the model-computed westward mean flow (Figures 6 and 7) is significantly stronger than the observed flow and prevents the plume from being transported any significant distance to the east ("upstream"). The source of the model error in the spring mean current has not been determined. Possible causes are discussed in the next subsection.

\subsection{Mean Flow}

[45] The persistent westward mean flow on the NES generally opposes the local wind stress, and is generally thought to be driven by large-scale remote forcing [Beardsley et al., 1985; Brown et al., 1985; Chapman et al., 1986; Shearman and Lentz, 2003]. Westward mean currents were found during other experiments, including the Nantucket Shoals Flux Experiment [Beardsley et al., 1985]. Plots of mean vertically averaged currents for the CMO period are shown in Figure 14. The current is westward and strengthens offshore, in agreement with observations [Shearman and Lentz, 2003]. As the model is able to capture the large-scale flow direction and magnitude on the timescale of the CMO period (Figure 6), it appears that the model, at least to first order, contains the proper alongshore pressure gradient. Seasonal mean currents (Figure 6), particularly for spring, are not as well resolved in the model. This indicates that the model does not resolve the correct seasonal variability of the large-scale alongshore pressure gradient or perhaps the low values of stratification in the model-computed density (Figure 5) do not allow offshore pressure gradients to properly influence flow on the shelf [Chapman et al., 1986; Csanady, 1985]. In May, when observed currents were persistently eastward, the model currents remained westward, but were significantly weakened. While investigation of this remote forcing in the model is beyond the scope of this work, it is likely to be partially driven by the wind-driven coastal setup/setdown condition used to influence the Scotian Shelf transport at the open boundary of the model domain (section 2.2.7). Future work will focus on model process-oriented experiments to examine the source and structure of the large-scale alongshore pressure gradient in the model and determine the effect of stratification, the wind field, and the open boundary on its seasonal variability.

\section{Summary}

[46] Findings from comparison of the FVCOM-GoM model-computed and observed hydrographic fields show that the magnitude and stratification of temperature and temporal history of the vertical distribution were all adequately captured in the $\mathrm{CMO}$ simulation. In the surface salinity field, the primary discrepancies are found during mid-May when the Connecticut River plume was able to reach the CMO central mooring site due to anomalously eastward wind stress. In the model-computed surface salinity, an overprediction of the westward mean flow prevented the plume from reaching the site.

[47] Notable distinct cross-shelf motions of the shelf slope front foot, evident in the observed winter density record are present in the model density fields, although weaker in magnitude. This indicates that the forcing driving 
the cross-isobath motion of the shelf slope front is present in the model.

[48] The mean vertically averaged model currents at the CMOC site were in very good agreement with observed results for the $\mathrm{CMO}$ period. Both magnitude and direction were accurately simulated. The model predicts the seasonal variations in fall and winter well but overestimates the strength of the spring mean current. There is strong agreement in profiles of along-isobath baroclinic geostrophic currents for the CMO period.

[49] Subtidal current variability has similar orientation (along-isobath) to observed but magnitudes are smaller for all seasons and comparable depths. This may be partially due to an underprediction in the wind stress variability. Seasonal subtidal current variability most closely matches the observed variability in spring when the wind stress is also in closest agreement. Several large current pulses occur during each season in the observed current fields which do not seem to be correlated with wind stress and are not represented in the simulation. These events are likely remotely forced, and thus their dynamical genesis is not properly modeled nor understood.

[50] The FVCOM-GoM model was able to resolve the correlation of wind direction and the vertically averaged currents. The model captures the broader shape of the lag in the fall and spring as well as the noted double peak in observed response in fall. Peak correlation occurred at about a 10-hr lag in the model data which was similar to observed and wind angle with maximum correlation ranged from $45^{\circ} \mathrm{T}$ to $60^{\circ} \mathrm{T}$ in accordance with previous findings on the NES [Beardsley et al., 1985; Shearman and Lentz, 2003].

[51] Acknowledgments. The authors would like to thank the reviewers for their helpful suggestions that have done much to improve the paper. For this work, G. Cowles was supported by the Massachusetts Marine Fisheries Institute (MFI) through NOAA grants DOC/NOAA/ NA04NMF4720332 and DOC/NOAA/NA05NMF4721131, S. Lentz by the NSF Ocean Sciences Division through grants OCE-841292 and OCE848961 , C. Chen and Q. Xu through the NSF/NOAA GLOBEC/Northwest Atlantic/Georges Bank Program under NSF grants OCE-0234545 and OCE-0227679 and NOAA grants NA-16OP2323, and R. Beardsley through NOAA grant NA-17RJ1223. The development of the FVCOMGoM model is a group effort. Thanks to Song Hu, David Stuebe, and Huichan Lin for their assistance in preparing the meteorological forcing database, objectively mapped daily satellite-derived SST fields, and model grids used in this study.

\section{References}

Allen, J. S. (1980), Models of wind-driven currents on the continental shelf, Annu. Rev. Fluid Mech., 12, 389-433.

Beardsley, R. C., D. C. Chapman, K. H. Brink, S. R. Ramp, and R. Schlitz (1985), The Nantucket Shoals Flux Experiment (NSFE79): I. A basic description of the current and temperature variability, J. Phys. Oceanogr. $15,713-748$

Brown, W. S., and R. Beardsley (1978), Winter circulation in the western Gulf of Maine: part 1. Cooling and water mass formation, J. Phys. Oceanogr., 8, 265-277.

Brown, W. S., N. R. Pettigrew, and J. D. Irish (1985), The Nantucket Shoals Flux Experiment (NSFE79): part II. The structure and variability of across-shelf pressure gradients, J. Phys. Oceanogr., 15, 749-771.

Burchard, H. (2002), Applied Turbulence Modeling in Marine Waters, Springer, New York.

Chapman, D. C., J. A. Barth, R. C. Beardsley, and R. G. Fairbanks (1986), On the continuity of mean flow between the Scotian Shelf and the Middle Atlantic Bight, J. Phys. Oceanogr., 16, 758-772.

Chen, C., R. C. Beardsley, and P. J. S. Franks (2001), A 3-D prognostic numerical model study of the Georges Bank ecosystem: part I. Physical model, Deep Sea Res. II, 48, 419-456.

Chen, C., H. Liu, and R. C. Beardsley (2003), An unstructured grid, finite-volume, three-dimensional primitive equation ocean model
Application to coastal ocean and estuaries, J. Atmos. Ocean. Technol., $20,159-186$

Chen, C., R. Wu, R. C. Beardsley, S. Hu, Q. Xu, and H. Lin (2005), Using MM5 to hindcast the ocean surface forcing fields over the Gulf of Maine and Georges Bank region, J. Atmos. Ocean. Technol., 22(2), 131-145.

Chen, C., Q. Xu, R. Houghton, and R. C. Beardsley (2008), A model-dye comparison experiment in the tidal mixing front zone on the southern flank of Georges Bank, J. Geophys. Res., 113, C02005, doi:10.1029/ 2007JC004106.

Cowles, G. W. (2008), Parallelization of the FVCOM coastal ocean model, Int. J. High Perform. Comput. Appl., 22(2), 177-193.

Craig, P. D., and M. L. Banner (1994), Modeling wave-enhanced turbulence in the ocean surface layer, J. Phys. Oceanogr., 24, 2546-2559.

Csanady, G. (1985), Pycnobathic currents over the upper continental slope, J. Geophys. Res., 15(3), 306-315.

Dickey, T., and A. J. Williams III (2001), Interdisciplinary ocean process studies on the New England Shelf, J. Geophys. Res., 106(C5), 9427-9434.

Fairall, C. W., E. F. Bradley, D. P. Rogers, J. B. Edson, and G. S. Young (1996), Bulk parameterization of air-sea fluxes for TOGA COARE, J. Geophys. Res., 101(C2), 3747-3764.

Fairall, C. W., E. F. Bradley, J. E. Hare, A. A. Grachev, and J. B. Edson (2003), Bulk parameterization of air-sea fluxes: Updates and verification for the COARE algorithm, J. Clim., 16, 571-591.

Grell, G. A., J. Dudhia, and D. R. Stauffer (1994), A description of the fifthgeneration Penn State/NCAR Mesoscale Model (MM5), Tech. Note NCAR/TN 398+STR, NCAR.

Houghton, R. W., F. Aikman III, and H. Ou (1988), Shelf-slope frontral structure and cross-shelf exchange at the New England shelf-break, Contin. Shelf Res., 8, 687-710.

Karypis, G., and V. Kumar (1998), METIS: A Software package for Partitioning Unstructured Graphs, partitioning Meshes, and Computing FillReducing Ordering of Sparse Matrices, Version 4.0.

Kobayashi, M. H., J. M. C. Pereira, and J. C. F. Pereira (1999), A conservative, finite-volume second order-accurate projection method on hybrid unstructured grids, J. Comput. Phys., 150, 40-45.

Lentz, S. J., R. K. Shearman, S. Anderson, A. Plueddemann, and J. Edson (2003), Evolution of stratification over the New England Shelf during the Coastal Mixing and Optics Study, August 1996-June 1997, J. Geophys. Res., 108(C1), 3008, doi:10.1029/2001JC001121.

Lynch, D. R., and C. E. Naimie (1993), The $M_{2}$ tide and its residual on the outer banks of the Gulf of Maine, J. Phys. Oceanogr., 23, 2222-2253.

MacKinnon, J. A., and M. C. Gregg (2002), Mixing on the late-summer New England Shelf-solibores, shear, and stratification, J. Phys. Ocean ogr., 33, 1476-1492.

Madala, R. V., and S. A. Piacsek (1977), A semi-implicit numerical mode for baroclinic oceans, J. Comput. Phys., 23, 167-178.

Mellor, G., and A. Blumberg (2004), Wave breaking and ocean surface layer thermal response, J. Phys. Oceanogr., 34(3), 693-698.

Mellor, G., and T. Yamada (1982), Development of a turbulence closure model for geophysical fluid problems, Rev. Geophys. Space Phys., 20, $851-875$.

MPI (1993), A message passing interface, MPI Forum, IEEE Computer Society Press.

Phillips, N. (1957), A coordinate system having some special advantages for numerical forecasting, J. Meteorol., 14, 184-185.

Pringle, J. (2006), Sources of variability in Gulf of Maine circulation, and the observations needed to model it, Deep Sea Res. II, 53, 2457-2476.

Ramp, S. R., R. J. Schlitz, and W. R. Wright (1985), The deep flow through the Northeast Channel, Gulf of Maine, J. Phys. Oceanogr., 15, 17901808 .

Schwing, F. B. (1989), Subtidal response of the Scotian Shelf bottom pressure field to meteorological forcing, J. Atmos. Ocean. Technol., 27, $157-180$.

Shearman, R. K., and S. J. Lentz (2003), Dynamics of mean and subtidal flow on the New England Shelf, J. Geophys. Res., 108(C8), 3281, doi:10.1029/2002JC001417.

Shearman, R. K., and S. J. Lentz (2004), Observations of tidal variability on the New England Shelf, J. Geophys. Res., 109, C06010, doi:10.1029/ 2003JC001972.

Simons, T. J. (1974), Verification of numerical models of Lake Ontario, part I: Circulation in spring and early summer, J. Phys. Oceanogr., 4, $507-523$.

Smagorinsky, J. (1963), General circulation experiments with the primitive equations: I. The basic experiment, Mon. Weather Rev., 91, 99-164.

Terray, E. A., W. M. Drennan, and M. A. Donelan (1999), The vertical structure of shear and dissipation in the ocean surface layer, Proc. Symp. on the Wind-driven Air-Sea Interface-Electromagnetic and Acoustic Sensing, Wave Dyn. Turbul. Fluxes, 239-245.

UNESCO (1981), Tenth report of the joint panel on oceanographic tables and standards, Tech. Rep. 36, UNESCO. 
Werner, S., R. C. Beardsley, and A. J. Williams III (2003), Bottom friction and bed forms on the southern flank of Georges Bank, J. Geophys. Res., 108(C11), 8004, doi:10.1029/2000JC000692.

R. C. Beardsley and S. J. Lentz, Department of Physical Oceanography, Woods Hole Oceanographic Institution, 266 Woods Hole, MA 02543-1541, USA.
C. Chen, G. W. Cowles, and Q. Xu, Department of Fisheries Oceanography, School for Marine Sciences and Technology, University of Massachusetts-Dartmouth, 706 S. Rodney French Boulevard, New Bedford, MA 02744-1221, USA. (gcowles@umassd.edu) 